\title{
Opportunities and barriers to multimodal cities: lessons learned from in-depth interviews about attitudes towards mobility as a service
}

\author{
Melinda Matyas (D)
}

\begin{abstract}
With the emergence of the Mobility as a Service (MaaS) concept, it is important to understand whether it has the potential to support behaviour change and the shift away from private vehicle ownership and use. This paper aims to identify potential ways that MaaS (specifically MaaS plans) could help encourage behavioural change; and understand the barriers to using alternative transport modes. In-depth interviews and qualitative analysis are applied to the case study of London. The results indicate that individuals segment the transport modes offered via MaaS into three categories: essential, considered and excluded. Soft measures should target each individuals' consideration set as this is where the most impact can be made regarding behaviour change. Respondents also highlighted factors that make them apprehensive towards certain modes, such as safety, service characteristics and administration. Interventions that focus on the socio-demographic groups that are most affected could help make these modes more appealing.
\end{abstract}

Keywords: Behaviour change, Transport policy, Mobility as a service, MaaS, Interviews, Qualitative analys

\section{Introduction}

Urbanization has caused people who wish to live in close proximity to business and commercial centres to flock to metropolitan areas. This increase in urban population has also been coupled with exponential growth in private vehicle usage over the past half a century [11]. However, historic European cities, which have developed over centuries, were not engineered to withstand such increased traffic densities. The resulting congestion and pollution issues have raised serious concerns and governmental bodies and city councils are eager to find solutions. A pivotal area of interest is the reduction of private vehicle ownership and use, which are well-documented contributors to traffic, air pollution and inefficient land use [21, 47, 48]. One solution, is to propose measures that promote the use of transport alternatives, thereby fostering behaviour change and decreasing private vehicle use and subsequently, their ownership. However, encouraging the shift away from private

Correspondence: Melinda.matyas@ucl.ac.uk

MaaSLab, Energy Institute, University College London, 14 Upper Woburn Place, London, WC1H ONN, UK vehicles is a challenging task as many people have strong preferences towards this mode and perceive this as the only option for meeting their needs [2]. As modern city dwellers' travel requirements are diverse, dynamic and demand flexibility, there is no single transport mode that can cater for them under all circumstances. Multimodal options are needed to service the unique travel requirements of each individual.

While public transport can provide an alternative to private vehicles in many occasions, it will not be able to solve all transport needs. Other modes, such as car sharing and bike sharing can provide valuable complements to public transport, while also providing a number of advantages. There is ample evidence on the positive effects of shared modes. Car sharing programmes significantly decrease VMT [8, 32], while bike sharing can also have positive effects on private vehicle use [12]. In many cases, those who use shared vehicles sell their own cars, delay vehicle purchase or do not even buy a vehicle in the first place leading to an overall decrease in private vehicle ownership $[8,12,41]$. Further, shared modes 
have shown to have a number of environmental and health benefits. Research has found, that the fuel economy of car sharing vehicles is more efficient than privately owned vehicles' [32]. As a result of this, and the decrease in VMT, car sharing can lead to significant reductions in greenhouse gas emissions [7, 32]. For example, Chen and Kockelman [7] found that car sharing members reduce their transport GHG emissions by approximately $51 \%$ when joining a car sharing service. In addition, bike sharing has a number of documented health benefits $[10,50]$.

For those situations where the above discussed public transport, car sharing and bike sharing alternatives cannot fulfil individuals' travel needs, other innovative travel solutions such as on demand taxi, pooled taxi, demand responsive transport are also available in a number of urban areas. Having such an assortment of options creates a complex transport system, where users can find it difficult to navigate through the silos of different information sources, mobile applications, tickets and journey planners that are necessary for them to get around [24]. The need for a single, integrated, user-friendly system has led to the birth of the Mobility as a Service (MaaS) concept, which aims to decrease the pain points that result from multimodal journeys. Based on the definition provided by MaaSLab [31] "Mobility as a Service is a user-centric, intelligent mobility management and distribution system, in which an integrator brings together offerings of multiple mobility service providers, and provides end-users access to them through a digital interface, allowing them to seamlessly plan and pay for mobility." For users, MaaS offers a single digital interface (e.g. an app) through which they can plan journeys and pay for and access all transport modes. MaaS also offers users MaaS products, such as monthly subscription plans which includes a predefined combination and amount of transport modes [18, 19, 23, 51].

This paper aims to contribute insights into the opportunities that MaaS can bring in supporting behaviour change while also providing observations regarding the barriers that hinder the uptake of individual modes. Taking London as a case study, in-depth interviews and qualitative analysis are carried out to explore individuals' evaluations of transport modes, namely public transport, bike sharing, car sharing and taxi, within MaaS plans. The key aims of the paper are to: (1) identify how MaaS could help encourage modal shift and behavioral change; and (2) understand the barriers to trying out and using certain modes through MaaS plans.

\section{Background and literature}

\subsection{Mobility as a service schemes}

Recently there has been a range of both commercial and pilot MaaS services appearing around the world.
Detailed reviews of these can be found in [14, 22, 23, 26, 30], however a brief description of their characteristics are presented below. Taking these reviews as a basis, the key elements of schemes are multimodal journey planning, real time information, integrated ticketing and payment, the inclusion of a number of different transport modes and an integrator organisation who is in charge of providing the services to users through a single platform. Looking at the structure of the services, there are two common approaches with regards to the type of entity that is the operator. First, there are those services where a private company is in charge of the integration (e.g. TransitApp, Moovel, Whim). In a number of cases, a commercial journey planning app is extended to have booking and ticketing functionalities, and the company owning the app naturally evolves into being the operator (e.g. My Cicero, Moovel). It is also possible, that a private company is created with the sole function of being a MaaS operator as in the case of Whim (the MaaS product of MaaSGlobal). The second common approach is that a public transport provider broadens its scope and offers the other functionalities (e.g. WienMobil Lab, Mobility Shop).

Regarding the core functionalities of the services, they frequently rest on a multimodal journey planner (e.g. Moovel, Whim). Real-time information is also a prominent feature, which goes hand in hand with multimodal journey planning. Payment (and invoicing), booking and ticketing functions are part of some, but not all services (e.g. WienMobi, Ubigo). In order to successfully achieve these for multiple mobility services, sharing of detailed information and APIs is necessary. This in some cases is further complicated by the fact that some services may not have, for example, electronic ticketing and payment systems, meaning it is very difficult it integrate them into such an technology intensive system. We can also find a number of cases where only certain transport modes are part of the payment, booking or ticketing systems(e.g. Optymod, TransitApp). Some of the services also include ad hoc functionalities, such as municipality services and Airplane schedules (e.g. MyCicero). All of the services are available on smartphone applications, which shows the power that these technologies have in the transport sector, but also raises some questions regarding its accessibility to certain population segments (elderly or technologically illiterate). With regards to the payment options, most services only provide pay-by-use options. However, CityMapper, UbiGo and Whim also provide monthly subscriptions (MaaS plans).

\subsection{Travel behaviour change and mobility as a service}

There are many studies that explore how public and shared modes can foster travel behaviour change. Most 
of these focus on a shift to a single mode (e.g. [3, 29]) although there are ones that look at the benefits of multiple modes together (e.g. [20]).

Due to the relative novelty of the MaaS concept, the available papers that focus on the user behaviour and behaviour change are fairly limited. A number of studies have resulted from the UbiGo MaaS field trial [28, 45]. In this trial, public transport, car sharing, taxi, bike sharing and car rentals were offered to users as subscription plans. 89 households with 195 users subscribed for monthly plans including a personalized combination ofand credit for- the various travel services. Regarding behaviour change, the Ubigo studies provide some evidence that participants increased their use of bike and car sharing and decreased private vehicle use [44].

There are also a couple of papers that study potential behaviour change in relation to MaaS in a hypothetical setting (as opposed to the field trial discussed above) [15, 34]. González Alonso, et al. [15] focus on whether MaaS could create modal shift. They do this, by carrying out an on-line survey in Amsterdam, in which participants are asked to choose transport modes in hypothetical situations. The study concludes, that multimodal users are most prone to adopt MaaS. One interesting element of this study, is that it does not directly ask respondents anything about MaaS. Rather, they use certain characteristics of individuals, namely public transport subscription, mobility app usage and opinion towards payment via applications, as a proxy of their willingness to adopt MaaS and change behaviour. Another study by Matyas and Kamargianni [34] use a stated preference experiments, discrete choice models and basic statistical analyses to examine the potential of MaaS bundles as a mobility management tool. Using London as a case study, they conclude that bundles could be used to promote the use of bike sharing and car sharing.

With MaaS gaining wider acceptance, it is important to understand whether it can have a role in promoting multimodality and the shift away from private vehicles. However, very few of the current studies tap into the large topic of MaaS's potential role in supporting behaviour change. This paper aims to add some additional insights into this subject.

\subsection{Qualitative travel behaviour analysis}

Qualitative methods are frequently used in subject areas such as sociology and phycology and have been employed to provide insights into individual and household decision making. It is less common in the field of transportation, where quantitative-only studies are more common. However, there are a number of benefits of conducting qualitative research. It can provide in-depth insights into the attitudes and perceptions of participants. During qualitative methods, individuals' own explanations of their thought processes can be collected, which can provide more detail than quantitative approaches [1,9]. While quantitative methods can provide insights into the relationships that emerge through the data, qualitative analysis can provide the reasons behind decisions and can include elements that the researcher may have not foreseen $[3,16]$. Qualitative analyses are especially useful to examine new topics, as responses are not restricted by the question and answer frame.

Looking at some examples of qualitative studies, Aicart et al. [1] provide a comprehensive overview of recent qualitative studies in the field of travel behaviour. They find that in-depth interviews are the most common method of qualitative data collection, while focus groups come second. The two methods are ideal in different situations. Focus groups should be used when the researcher is interested in understanding the interactions between individuals (such as empathy or disagreement) or when the group setting may bring out more insights ([16]; Lazar, et al., 2017). However, individuals may be less keen to share their views when others are present, especially when they may contradict the general tendency of the group. Personal interviews remove the normative pressures and allows for flexible types of information to be collected [9]. In their review, Aicart et al. [1] also examine the analysis techniques that studies employ when dealing with qualitative data. They find that the most frequently applied method is thematic analysis, in which the data is explored, to identify, analyse, organize and describe the themes and patterns that emerge ([5]; Nowell, et al., 2017).

As discussed above, qualitative analysis can have a number of advantages. Looking at MaaS, there are only very few studies that take this in-depth approach to examining the topic. Two studies use individual meetings and semi structured interview, however both of these focus on the supply side [42, 43]. The only paper that the author is aware of that looks at behaviour and uses qualitative analysis is the above-mentioned Karlsson et al. [28] study that involve interviews and focus groups with with particiapnts of the Ubigo field trial. This leaves pleanty of room for further analysis on the topic, which this paper aims to contribute to.

\section{Methods}

\subsection{Study design}

Respondents were asked to complete an online survey (results are out of the scope of this paper; please see [35] for details), followed by in-depth semi-structured interview. These were completed one after the other, meaning that the respondent was given access to a computer and left to complete the survey and once finished, was joined by the researcher for the interview. The survey included a section that introduced participants to the 
Table 1 Semi-structured questions and prompts used in interview

\begin{tabular}{|c|c|c|c|}
\hline Section & Priority area & Main question & Follow-up prompts \\
\hline $\begin{array}{l}\text { Foundation } \\
\text { questions }\end{array}$ & $\begin{array}{l}\text { Understanding of the } \\
\text { MaaS concept }\end{array}$ & $\begin{array}{l}\text { Could you describe in your own words } \\
\text { what Mobility as a Service (MaaS) is? }\end{array}$ & $\begin{array}{l}\text { - What are the main features of MaaS? } \\
\text { - How would it work in practice? }\end{array}$ \\
\hline $\begin{array}{l}\text { Primary } \\
\text { questions }\end{array}$ & $\begin{array}{l}\text { Evaluation criteria of } \\
\text { MaaS plans }\end{array}$ & $\begin{array}{l}\text { What was going through your mind } \\
\text { when you were choosing between the } \\
\text { presented MaaS plans? }\end{array}$ & $\begin{array}{l}\text { - Most important factors you were looking for when } \\
\text { considering the plans? } \\
\text { - Anything you were specifically looking for and why? } \\
\text { - Anything that specifically discouraged/deterred you from } \\
\text { choosing certain plans and why? } \\
\text { - Specific modes? } \\
\text { - Additional features? } \\
\text { - Price vs mode tradeoff? }\end{array}$ \\
\hline $\begin{array}{l}\text { Secondary } \\
\text { questions }\end{array}$ & $\begin{array}{l}\text { Overall attitude towards } \\
\text { MaaS }\end{array}$ & $\begin{array}{l}\text { Overall, what was your impression of the } \\
\text { MaaS concept in general? }\end{array}$ & $\begin{array}{l}\text {-Would you be interested in signing up? } \\
\text { - What would make you more interested? } \\
\text { - Are there any barriers? } \\
\text { - Anyone you know who would be interested? }\end{array}$ \\
\hline
\end{tabular}

MaaS concept and presented them with a number of MaaS plans to choose from. Each MaaS plans included a variety of different transport modes bundled together into a package. Thorough this process, they could familiarise themselves with the concept and MaaS plans, and were able to provide informed insights about it during the interview.

The interview was semi-structured, based on preprepared main questions and follow-up prompts (see Table 1). There were three priority areas which were carefully selected based on elements of MaaS where the in-depth qualitative analysis could provide valuable insights. Each of the three priority areas had one main question and 2-6 predefined follow-up questions. That being said, based on the discussions, additional follow up questions were also included at the discretion of the interviewer.

\subsection{Data collection and analysis}

To recruit participants a mix of convenience and purposive sampling was used to ensure that a wide range of views were heard. The sample size is fairly limited, however the purpose of the qualitative research is not to gain a representative sample, but to illustrate important themes that may arise (and can be examined further in future research). ${ }^{1}$ A total of 30 individuals, who lived within Greater London and were over 18 were selected. The characteristics of the participants can be seen in Table 2. While the participants have differing characteristics, the sample is not meant to be representative of the London population. For example, the sample does not include anyone in the age group $65+$ group as the focus of the paper is on solely on working-age

\footnotetext{
${ }^{1}$ Limited sample sizes (between 20 and 40 participants) are frequently used in qualitative studies, especially when using in-depth interviews. For some examples, please refer to the summary tables presented in Aicart et al. [1].
}

population. ${ }^{2}$ Also, the sample is has a higher average education level than London, where according to the 2011 Census only about $10 \%$ of the population had university degrees or equivalent. These characteristics may have an impact on individuals' views on MaaS which should be taken as a caveat when interpreting the results.

The data collection took place during June-July 2018 and was conducted by a single interviewer to ensure consistency and coherency. Each interview lasted between 45 and 75 min depending on how long it took to fill out the survey and how involved the participant was. Each interview was digitally recorded with written consent by the participant.

Thematic analysis was used for during the study [5]. To do so, the interviews were transcribed into the NVivo qualitative data analysis software. Aided by the software, the transcripts were thoroughly scrutinized and relevant concepts were appropriately coded. The codes were organised hierarchically, which resulted in a topology of related concepts. By re-reading the transcripts and refining the codes, a number of themes emerged, which were then further refined to arrive at a final set of relevant themes.

\section{Results}

The results are broken down into three main topics. First the process by which respondents' evaluated the modes in the plans is presented. Next, respondents' reasons for disfavouring certain modes is described, which can provide observations regarding pain points of various transport modes. Third, respondents' general thoughts on the MaaS concept as a whole and whether it could support behaviour change is presented. Quotations are provided to illustrate themes and related concepts and an identifier is used to

\footnotetext{
${ }^{2}$ While working-age population is commonly defined from 15 to 64 (e.g. by the OECD), this paper excludes individuals under 18 .
} 
Table 2 Characteristics of participants

\begin{tabular}{|c|c|c|}
\hline Characteristic & Group & $\begin{array}{l}\text { Number of } \\
\text { participants }\end{array}$ \\
\hline Gender & $\begin{array}{l}\text { Male } \\
\text { Female }\end{array}$ & $\begin{array}{l}13 \\
17\end{array}$ \\
\hline Age & $\begin{array}{l}18-25 \\
26-45 \\
45-65 \\
65+\end{array}$ & $\begin{array}{l}9 \\
11 \\
10 \\
0\end{array}$ \\
\hline Nationality & $\begin{array}{l}\text { British } \\
\text { EU } \\
\text { Other }\end{array}$ & $\begin{array}{l}28 \\
2 \\
0\end{array}$ \\
\hline Education & $\begin{array}{l}\text { Under bachelors } \\
\text { Bachelors degree } \\
\text { Masters degree } \\
\text { Above Masters } \\
\text { degree }\end{array}$ & $\begin{array}{l}9 \\
11 \\
7 \\
4\end{array}$ \\
\hline Employment & $\begin{array}{l}\text { Full time job } \\
\text { Part time job } \\
\text { Student } \\
\text { Other }\end{array}$ & $\begin{array}{l}14 \\
6 \\
7 \\
3\end{array}$ \\
\hline Household income & $\begin{array}{l}\text { Under } £ 25,000 \\
£ 25,000-£ 50,000 \\
\text { Over } £ 50,000 \\
\text { Prefer not to answer }\end{array}$ & $\begin{array}{l}9 \\
5 \\
9 \\
7\end{array}$ \\
\hline Household composition & $\begin{array}{l}\text { No children } \\
\text { Children }\end{array}$ & $\begin{array}{l}13 \\
17\end{array}$ \\
\hline $\begin{array}{l}\text { Household vehicle } \\
\text { ownership }\end{array}$ & $\begin{array}{l}\text { Yes } \\
\text { No }\end{array}$ & $\begin{array}{l}19 \\
11\end{array}$ \\
\hline Household vehicle driver & $\begin{array}{l}\text { Yes } \\
\text { No }\end{array}$ & $\begin{array}{l}17 \\
13\end{array}$ \\
\hline
\end{tabular}

indicate the characteristics of the respondent. The code represents the respondents characteristics as presented in Table 3.

\subsection{Respondents' evaluations of modes in the plans} The analysis of the transcripts revealed that respondents evaluated the transport modes in each MaaS plan by sorting them into three categories:

(1) Essential: modes that were deemed as critical elements of MaaS plans and participants would not conider plans without these.

(2) Considered: modes that respondents would consider having in their plans but are not essential.

(3) Excluded: modes that respondents actively tried to exclude from their plans and would not even consider plans with these modes in them.

Table 3 Coding for individual identifiers

\begin{tabular}{llllllll}
\hline Gender & Age & \multicolumn{2}{l}{ Vehicle use } & Employment & \multicolumn{2}{l}{ Children } \\
\hline M male & $18-28$ & D & driver & FT & full time & C & children \\
F female & $26-45$ & ND & non-driver & PT & part time & NC no children \\
& $46-65$ & & & S & student & & \\
& & & & &
\end{tabular}

\subsubsection{Essential modes}

Twenty-one respondent very clearly referred to the fact that there were modes that they immediately looked for in their plans. Those modes that respondents frequently used were deemed as critical elements of MaaS plans and would not choose plans without these:

"The first thing I looked at was whether they had public transport and the second thing was whether they had the bike sharing because they are the two things that I use every day at least twice a day so they had to be in the plan really." M|18$24|N D| S \mid N C$

"The main one for me is public transport, and then the other one for me is access to a car, whether it be my own car or a shared one, I would need it because on the weekends I like to have a car and drive out of the city. So those are the two really important things to me." $F|45-54| D|F T| N C$

As illustrated by the quotes above, habit plays an important role when choosing between MaaS plans. Through the discussions, it became clear that the first element people would think about is the transport modes they use for their daily commutes as well as those they may use on a regular basis. In all cases, these resulted between 1 and 3 essential modes, without which, respondents would not even contemplate choosing a plan. This does not come as a surprise, as it has been widely documented that travel is a habitual behaviour [39, 40]. Another important element can be seen through the quotes above, and that is the importance of public transport. Almost all respondents, regardless of whether they are car drivers or not, stated that public transport is an essential part of their travel patterns and would only consider buying MaaS plans that included this. While the preference towards public transport is clear in this specific case, it is not possible to conclude whether this is unique to London or the same would hold in other cities with different transport systems and demographic characteristics.

\subsubsection{Considered modes}

The second category of modes were those that respondents would be willing to consider in their plans. 12 respondents used words such as "consider", "probably", "maybe", "don't use it but like the idea" etc. Some of these modes they may have used before, but are not an essential element of their modality portfolio: 
"The only bit of all of that that I would consider doing is using the bikes when I am in London." $M|55-64| D|R| N C$

"Taxi was just an added bonus." $M|18-24| N D|S| N C$

"I did consider it [bike sharing], but it's not a big one for me." $F|18-24| D|S| N C$

In other cases, respondents revealed that they would be willing to consider modes in their MaaS plans that they may have never tried before, or currently do not use. In these situations, MaaS plans could provide people with easy access to new modes such as bike or car sharing:

"Bike sharing would be the third mode I would actually involve in my plan because, although I currently don't use it, it would be nice to know that I have an option with just a minor change in the price to have this option as well." M|25-34|ND|FT|NC

"The car sharing, since I've never used one, yes that's something I could consider, but it would have to be that flexibility and speed of access and that it's not too far to walk to get one." $F|35-44| D|F T| C$

As illustrated by these example quotes, MaaS could be a platform to get individuals using several different types of transport modes. Some which they rarely use, or others that they may not use at all. This middle category of modes, the "considered modes" is where MaaS could truly make an impact with regards to behavioural change.

\subsubsection{Excluded modes}

The third category of modes were those that participants completely eliminated from their evaluations. 12 participants expressed clear disfavor towards certain modes. These respondents used prases like "eliminate", "don't want", "would never use", "get rid of", "no point of having" to describe tese modes.

They also stated that any plan that included those modes would be excluded from their choice set:

"I don't feel comfortable actually being the driver, so that eliminated any car shares and I also don't feel comfortable riding a bike in the city so that eliminated that, so it was pretty much anything that didn't involve me as a driver so public transport and taxi services is what I would be interested in more than using the others." $F|25-34| D|F T| C$

"I wouldn't use even if they were available. I mean things like car sharing or bike sharing - I've got my own bike, so if I wanted to cycle somewhere I would use that and I have my reasons why I don't tend to cycle around London and that wouldn't change even if there was a cycle share option. And similarly with the car sharing, I think if I didn't have a car, I would probably just do without - I can't really see a scenario in which I would chose to join a car club." $F|45-54| D|F T| N C$

The quotes above demonstrate that many respondents had very strong oppositions towards certain modes. Through the discussions, it became clear, that these were embedded into their thoughts and it would be difficult to change these.

It is important to understand that the essential, considered and excluded modes are different for every person. Through the discussions, it became clear that prior experiences significantly shape individuals' preferences for certain modes. Overall, it was evident that for almost all participants public transport played is essential. The considered category contained all the remaining three transport modes taxi, bike sharing and car sharing. The excluded category included bike sharing and car sharing, depending on the specific person. Taxi and public transport was almost never mentioned as excluded category.

\subsection{Respondents' reasons for disfavouring certain modes}

The analysis revealed some interesting insights about the reasons why individuals disfavoured certain transport modes from their MaaS plans. Understanding these reasons can give some important insights into characteristics of these services that need to be improved in order for more people to use them. An overview of the different themes can be found in Table 4 alongside example quotes and the number of respondents who mentioned each theme.

The first key theme that emerged through the analysis of the transcripts was the frequent mentions of safety concerns when it comes to driving and especially cycling around London. These concerns were especially prominent when women were talking about their apprehension towards using these modes. Many people (11) commented on the fact that their perception of cycling in London is quite negative and that they are too scared to ride them outside of parks. Several people (4) mentioned 
Table 4 Reasons for disfavouring modes

\begin{tabular}{|c|c|c|}
\hline Theme & Example quotes & $\begin{array}{l}\text { Numerber of } \\
\text { respondents }\end{array}$ \\
\hline Safety concerns & $\begin{array}{l}\text { "I think I would be quite frightened cycling in London. I don't trust drivers, buses." F|45-54|ND|FT|C } \\
\text { "I would like the roads to be improved and be a bit more safe. You see so much in the TV people in the } \\
\text { middle of the road getting knocked of their bikes because drivers aren't paying attention. Especially as a } \\
\text { driver, you can see it, it's getting worse and worse - driving is atrocious. We were actually just having a } \\
\text { conversation with my family the other day about how appalling London drivers are now. They could } \\
\text { even take your life in a car, god knows with a bike or motorbike." F|35-44|D|FT|NC }\end{array}$ & 11 \\
\hline $\begin{array}{l}\text { Uncertainties about service } \\
\text { characteristics }\end{array}$ & $\begin{array}{l}\text { "Maybe if it was something that was available in the area and it was a definite that I could always } \\
\text { access it, then I would definitely consider getting rid of my car and using a car share if it had the things } \\
\text { that I need - if I knew that there was always going to be a baby seat in the trunk or something that I } \\
\text { could use and then if it was close." F|35-44|D|FT|C } \\
\text { "But obviously, for a lot of families it would nice to have a plan where if you ordered a big enough cab } \\
\text { with a child seat or one which you can put your buggy in. Or especially, I have a few friends with dogs } \\
\text { and they find it difficult to get a cab because not all of the cabs would take a dog on. So that would } \\
\text { be a nice feature that you could just tick that you would want a dog friendly car." F|35-44|ND|PT|C }\end{array}$ & 8 \\
\hline Lost trust in service & $\begin{array}{l}\text { "I had a bad experience with it [car sharing]. The car wasn't there - the previous people had overrun and } \\
\text { I was desperate to use the car. And then I was told where it was and it was locked, so it was just very } \\
\text { difficult. And then I lost confidence a bit." F|45-54|D|FT|C } \\
\text { "Black cabs have created apps, but it depends on the quality of the app. And I've tried to use the black } \\
\text { cab apps and there are never any available and they are not where they say they will be. So I like the } \\
\text { technology and obviously Uber has nailed it and it is just so much." F|45-54|D|FT|NC }\end{array}$ & 5 \\
\hline $\begin{array}{l}\text { Annoyance with } \\
\text { administration }\end{array}$ & $\begin{array}{l}\text { "I guess, like the bike share, that's quite easy in itself that you can do on an app quite quickly but the } \\
\text { car you tend to think that that will be a really long process." M|25-34|D|FT|NC } \\
\text { "I have used everything before, I have used the Zipcars and I found it useful at the time, because I didn't } \\
\text { have a car, but I had to take my children to school or do a shop, but still something that worried me } \\
\text { with all these things like Zipcar, you need an app and are a lot of hoops to jump through to be able to } \\
\text { use it so it's a bit intimidating, so I thought maybe this new plan may take away some of the admin } \\
\text { and that would be a good thing. And then I would definitely use things more if I didn't have to go } \\
\text { through as many hoops and obstacles." F|45-55|D|FT|C }\end{array}$ & 6 \\
\hline $\begin{array}{l}\text { Preference towards own } \\
\text { bike or car }\end{array}$ & $\begin{array}{l}\text { "It's a good idea, but I prefer my own bike because it's my own and if there is no base for those bikes I } \\
\text { need to find somewhere else for them. For my own bike I can just lock it up anywhere so it's easier." } \\
\text { M|18-24|ND|S|NC } \\
\text { "It's comfort. I can get into my car straight outside of my house. I don't need to work towards anyone } \\
\text { else's schedule, I am running to my own schedule. I have a lot to carry so something door to door is } \\
\text { handy for me." F|25-34|D|FT|C }\end{array}$ & 6 \\
\hline
\end{tabular}

that they would love to cycle more and they like the concept of bike sharing, however they are too nervous to do so. One participant also said that they are not keen to cycle in London because of the bad air quality. Some (4) respondents also mentioned safety as a concern when discussing driving and car sharing, however this was not as prominent as in the case of cycling.

The second theme that emerged was the fact that people were reluctant towards using services because they were unsure about all the available features. This was especially prevalent when it came to individuals with special needs, such as families or pet owners. These respondents expressed that they would be much more open to using these if they would be ensured that all their needs would be met.

Third, although this was not prominent, a few respondents (5) pointed out that due to a bad experience, they are no longer interested in using a service. These examples show, that with all the available services nowadays, people do not have to stick with one service if they do not feel comfortable with it. People lose trust in a service quite easily, and expect constant high quality. This is especially true for new, innovative services, where people are quite unforgiving towards bad services. The discussions showed strong emotional experiences. Fourth, during the interviews, when discussing shared modes, the hassle and administration side of using these services was brought up on a number of occasions (6). Respondents mentioned that the complexity of using these services significantly discouraged them from using them. Fifth, for private car and cycle owners, some respondents (6) had strong preferences towards using their private vehicles and bicycles. These were mainly for practical reasons, such as being able to store personal effects in the car or being able to leave them wherever they want.

\subsection{Respondents' thoughts on the MaaS concept and behavior change}

When respondents were describing the overall MaaS concept and what they think about it, some interesting themes emerged. There are three main themes that point towards the fact that individuals believe that MaaS could in fact help encourage modal shift. 


\subsubsection{Maas increases awareness of modes}

The analysis of the transcripts revealed, is that respondents (7) focused a lot on exposure to new modes when they were discussing the MaaS concept. A characteristic that was frequently mentioned with a positive connotation, is the fact that MaaS increases awareness of the various transport options that are available in London. Some participants even noted that they had not heard of certain modes (e.g. car clubs) before, but think that MaaS would be a great way for them to be introduced:

"Making users aware of all potential modes of transport that they may not have seen before. I did enjoy the fact that it seemed like it would give me an easy way of being introduced to certain things that I've always been intrigued by when I see them on the street." M|25-34|D|FT|NC

"Using more public transport that's available and different methods that are available but you may not know about." $F|35-44| D|F T| N C$

\subsubsection{MaaS changes the perception of the choice set available}

Another aspect that materialized from the analysis of the transcripts is that MaaS can expand respondents' perceived choice set. Through the discussions it became clear that many respondents (9) were aware of the existence of the various modes but they never (or rarely) considered this as part of their choice set. With MaaS, the decision is still in the hand of the traveller, but their perception of the array of options that they can choose from is modified:

"To give members of the public a choice of not just those that are probably seen as the usual modes of transport (the train, tube) but also car sharing, bike sharing." $M|25-34| D|F T| N C$

"Trying something that you perhaps haven't tried before - I think that for me it would be borrowing bikes." F|45-54|ND|FT|C

"It is the concept of involving many different forms of transport, or public transport, together for members of the public to be able to use or choose from." $M|25-34| D|F T| C$

\subsubsection{Maas could decrease private vehicle use}

The final theme that was prominent in several respondents' (6) descriptions of MaaS is the fact that MaaS could have an impact on private vehicle use. It is important to note, that there were questions in the survey that aimed at getting respondents thinking about what effect MaaS could have on private vehicle use, which may have caused respondents to think about this aspect more than they would have otherwise. Nevertheless, it is interesting that many respondents, regardless of whether they were car drivers or not, specifically pointed towards MaaS decreasing dependence on private vehicles:

"I think it would definitely promote people to use this over their cars which is good." M|18$24|N D| S \mid N C$

"For example, my sister, she has got a car sitting outside and she never uses it because she takes the tube to and from work, so it's pointless of her having a car. So this sort of thing would be ideal for her. The times when she does need a car or a weekend away, she could just use this." F|55-64|D|PT|C

\section{Discussion and policy implications}

This study provides early insights into attitudes and perceptions regarding MaaS's role in promoting behaviour change and the barriers of adopting certain modes through MaaS plans. The above-presented themes have a number of important implications regarding areas where policy interventions would be most effective. The themes also highlight some priority areas for future research.

The analysis showed that respondents classify the modes within MaaS plans into three categories based on how interested they are in them. 'Essential' modes are those which are pivotal and they most likely already frequently use; 'considered' modes are those that they would be willing to include but may not yet use; and 'excluded' modes are those that they definitely do not want in their plans and would eliminate any plan that included these. Based on these findings, policy measures should be targeted towards encouraging individuals to include their 'considered' modes in their plans as this is where the most potential for behaviour change lies. As the 'considered' modes for each individual is unique, there is a need for segmentation based on attitudes and behaviours (the concept of segmentation is in line with previous research; see $[2,46])$. Strategies promoting each mode should be targeted at those individuals who are 'considering' these as this is where it will have the highest impact. There is potential for MaaS plans to provide 
the platform for targeted marketing campaigns promoting those modes specifically that each user is willing to consider. This is also an area of future research, as the exact 'consideration' set for each socio-demographic user group is still unknown. Further, the characteristics, attitudes and perceptions of individuals that influence 'consideration' (for example prior experiences) need to be examined in more depth, to be able to clearly identify which modes to target for each person.

Turning to the analysis on the factors that emerged as causing unease towards certain modes, these findings can support policies aimed at the individual services as well as the services within MaaS systems. The first key point is safety, which was a very prominent theme throughout the interviews, especially in terms of cycling. Women in particularly expressed concerns with drivers and how they do not feel confident enough to try to cycle on London's roads. A number of respondents spontaneously pointed out that they do not have a problem with cycling per se and would actually really like to cycle more, but their anxiety of being in an accident outweighs this. The elements of safety that was especially notable is traffic and fear of car drivers, buses and other transport modes. The perception of cycling safety is a significant barrier in increasing the mode share of both personal cycle and cycle sharing use [6,38]. Regarding policy implications, mixed traffic infrastructure layouts are perceived less safe but a sustained level of cycling infrastructure investment can help create the perception of a safer environment [27]. Cycle tracks and buffered cycle lanes can improve safety perceptions, especially for women [13, 36]. Looking at this insight through the MaaS plan setting, the MaaS app and journey planner could be used to guide users through safer cycle routes and away from high traffic intersections.

The second aspect that emerged through the interviews was that individuals seem to be uncertain about the characteristics of the services themselves. This is especially prevalent with participants with special needs (e.g. parents of small children, pet owners). In order for them to be comfortable and confident using these services, they need to be ensured that they have all the necessary features. This aligns with findings from other studies where information issues and lack of awareness and understanding have been mentioned as barriers to adoption [17, 49]. This is also an important insight for individual service providers, who may be losing out on a significant number of users because they cannot guarantee elements, such as child seats, in their vehiclesMaaS could provide the platform where users can select the service characteristics suit their needs.

The third finding is that respondents lose trust in services fairly easily and even one bad experience can discourage them from using the service ever again. New services should be encouraged to do 'soft' launches or alpha and beta test runs before large scale introductions. Also, policies that support customer protection could be made more prominent, in order to encourage minimal service disruptions.

The fourth element that respondents mentioned as a deterring factor from certain modes is the annoyance with administration that comes hand in hand with these modes. This is also in line with previos findings from literature looking at barriers to adopting individual modes $[4,37]$. Strategies that support the safe, but streamline administrative processes of trying out and using new services could definitely aid in their uptake. This is where MaaS could also play an important role by centralising all administrative processes and allowing users to use a single app and verification process for all services (even multiple services for the same transport mode e.g. multiple car sharing service providers). This would require services to accept and adhere to a centralised solution and the central verification agency would need to ensure unbiased and prompt responses.

The fifth, and final, theme about disfavour towards certain shared modes, is that some individuals have strong preferences towards using their own bike or car. For example, some car users are self-proclaimed car addicts and have a psychological dependence on private vehicles [2]. Policies that aim at shifting individuals to car sharing should target market segments that are willing to change. Those individuals who are emotionally attached to their cars will have no intention to change their behaviour and any sort of policy approach or marketing campaigns promoting car sharing targeted towards this group would probably not be successful [3]. With regards to MaaS plans, as these modes are most likely "excluding" modes (that is, any plan with them would be all together eliminated) it is important to create methods to detect who these individuals are, and propose MaaS plans to them that do not include car sharing.

Turning to respondents' thoughts on the MaaS concept and whether they believe it is able to support behavioural change, overall there was a positive attitude towards the possibilities that lie ahead. The discussions revealed that many respondents believe that MaaS would increase their awareness of new modes and the perception of the choices available to them. With the number of new modes and service offerings constantly increasing respondents mentioned how difficult it is to keep up with all the available options. MaaS could provide a streamlined, simplified solution to the introduction of new services to the general population. Even services that have been around for a while may be able to benefit by tapping into a new customer segment due to the decrease in administrative burdens (e.g. separate 
registration, apps, journey planners). MaaS could provide the single, integrated, personalised information source to allow urban commuters to make the most of all the transport modes in a city without being intimidated by the available options. As such, policies should be put in place that support the sharing of information and APIs (application programming interfaces) that enable such centralised solutions to flourish [25, 33]. Further, several participants explicitly mentioned that MaaS could help promote less private vehicle use and ownership, although this would be as an indirect result of the use of other modes.

An element worth poining out based on the analysis above is that a MaaS system will potentially have to overcome the barriers of several individual modes for people to start using it. When tying to promote use of a single mode, there are clear barriers that need to be addressed. However, when looking at MaaS, the combination of modes adds an extra layer of complexity in that the concerns of each individual service should be tackled. This may be quite a difficult task, especially in the case where the MaaS business model includes a variety of different service providers and where the contractual obligations within the MaaS scheme are limited.

\section{Conclusions}

To conclude, the study used in depth interviews with individuals to investigate how MaaS could help encourage behavioral change and understand the barriers to trying out and using certain modes. Interventions should target each individuals "consideration" set, as these are those where behavior change policies will be most successful. There are a number of factors that make specific modes unattractive to certain individuals, which can be improved by targeted strategies. Overall, there was a positive attitude towards the role MaaS could play in helping behavior change and the decrease in private vehicle dependence. It is also clear, that there could be supporting policies that make it easier and more desirable to use the various multimodal solutions. This research is only a small step towards understand the opportunities that MaaS can bring.

There are a number of limitations in the present study. First, only a small sample of participants were used. Second, it is a geographically specific research, as such, findings should not be generalized. Third, it should be noted that as more applications become available and the wider population have direct experiences with this service, their attitudes may shift. Even with these limitations, this research does provide some valuable initial insights into the role MaaS could have in supporting behavior change. As the concept matures and more real life applications develop there will be room for further in-depth research about the exact ways that the concept can be used to support the shift away from private vehicles.

\section{Acknowledgements}

The author would like to thank Dr. Maria Kamargianni for her support during the writing of this paper.

\section{Authors contribution}

MM completed all elements of the research presented in this paper. All authors read and approved the final manuscript.

\section{Funding}

This research was supported by the UK EPSRC.

\section{Availability of data and materials}

The transcripts generated during the current study are not publicly available to ensure the confidentiality of the research participants. However, they are available from the corresponding author on reasonable request (but will be anonymised to ensure no participant is identifiable).

\section{Competing interests}

The authors declare that they have no competing interests.

Received: 8 July 2019 Accepted: 15 January 2020

Published online: 07 February 2020

\section{References}

1. Aicart, M., del Lidón, M., Arroyo-López, M. R., \& Ruiz Sánchez, T. (2016). Qualitative research in travel behavior studies. Transportation Research Procedia, 18, 434-445.

2. Anable, J. (2005). 'Complacent car addicts' or 'aspiring environmentalists'? Identifying travel behaviour segments using attitude theory. Transp Policy, 12(1), 65-78.

3. Beirão, G., \& Sarsfield-Cabral, J. A. (2007). Understanding attitudes towards public transport and private car: A qualitative study. Transp Policy, 14(6), 478-489.

4. Bielefeldt, J., Poelzl, J., \& Herbst, U. (2016). What's mine Isn't yours-barriers to participation in the sharing economy. Die Unternehmung, 70(1), 4-25.

5. Braun, V., \& Clark, V. (2006). Using thematic analysis in psychology. Qual Res Psychol, 3(2), 77-101.

6. Chataway, E. S., Kaplan, S., Nielsen, T. A. S., \& Prato, C. G. (2014). Safety perceptions and reported behavior related to cycling in mixed traffic: A comparison between Brisbane and Copenhagen. Transport Res F: Traffic Psychol Behav, 23, 32-43.

7. Chen, T. D., \& Kockelman, K. M. (2016). Carsharing's life-cycle impacts on energy use and greenhouse gas emissions. Transp Res Part D: Transp Environ, 47, 276-284

8. Clewlow, R. R. (2016). Carsharing and sustainable travel behavior: Results from the San Francisco Bay Area. Transp Policy, 51, 158-164.

9. Clifton, K., \& Handy, S. (2003). Qualitative methods in travel behaviour research. Kruger Park, South Africa, pp, 283-302.

10. Rojas-Rueda, D., de Nazelle, A., Tainio, M., \& Nieuwenhuijsen, M. J. (2011). The health risks and benefits of cycling in urban environments compared with car use: Health impact assessment study. Br Med J, 343, 4521.

11. Department for Transport. (2017) Trasport Statistics Great Britain 2017.

12. Fishman, E., Washington, S., \& Haworth, N. (2014). Bike Share's impact on Car use: Evidence from the United States, Great Britain, and Australia. Transp Res Part D: Transp Environ, 31, 13-20.

13. Garrard, J., Rose, G., \& Lo, S. K. (2008). Promoting transportation cycling for women: The role of bicycle infrastructure. Prev Med, 46(1), 55-59.

14. Georgakis, P. et al., 2018. Deliverable 2.3 - MaaS4EU use cases and reference architecture of the EU H2O20-funded project.

15. González Alonso, M., van Oort, N., Cats, O., \& Hoogendoorn, S. (2017). Urban demand responsive transport in the mobility as a service ecosystem: Its role and potential market share. Paper presented at the Thedbo conference. Sweden: Stockholm.

16. Grosvenor, T. (2000) Qualitative research in the transport sector. Resource paper for the Workshop on Qualitative/Quantitative Methods.

17. Hazée, S., Delcourt, C., \& Van Vaerenbergh, Y. (2017). Burdens of access: Understanding customer barriers and barrier-attenuating practices in access-based services. J Serv Res, 20(4), 441-456.

18. Hensher, D. (2017). Future bus transport contracts under a mobility as a service (MaaS) regime in the digital age: Are they likely to change? Transp Res A, 98, 86-96. 
19. Hietanen, S. (2016). Mobility as a service' - The new transport model? Eurotransport, 12(2), 133-176.

20. Huwer, U. (2004). Public transport and car-sharing-Benefits and effects of combined services. Transp Policy, 11(1), 77-87.

21. Jeekel, H. (2016). The car-dependent society: A European perspective. Routledge.

22. Jittrapirom, P., Caiati, V., Feneri, A. M., Ebrahimigharehbaghi, S., Alonso González, M. J., \& Narayan, J. (2017). Mobility as a service: A critical review of definitions, assessments of schemes, and key challenges.

23. Kamargianni, M., Li, W., Matyas, M., \& Schäfer, A. (2016). A critical review of new mobility services for urban transport. Transportation Research Procedia, 14, 3294-3303.

24. Kamargianni, M., Matyas, M., Li, W. and Schafer, A. (2015) Feasibility study for "mobility as a service" concept in London. MaaSLab - UCL energy institute report, prepared for Department for Transport.

25. Kamargianni, M. and Matyas, M. (2017) The business ecosystem of mobility as a service. 96th Transportation Research Board (TRB) Annual Meeting, Washington DC, 8-12 January.

26. Kamargianni, M., Yfantis, L., Muscat, J., Azevedo, C.M.L. and Ben-Akiva, M. 2019. Incorporating the mobility as a service concept into transport modelling and simulation frameworks. In the Transportation Research Board (TRB) 98th annual meeting

27. Kaplan, S. and Prato, C. G. (2013) 'Them or us: Perceptions, cognitions, emotions and overt behavior associated with cyclists and motorists sharing the road' presented at the 92nd annual meeting of the Transportation Research Board, Washington, DC.

28. Karlsson, A., Sochor, J., \& Strömberg, H. (2016). Developing the 'service' in mobility as a service: Experiences from a field trial of an innovative travel brokerage. Transportation Research Procedia, 14, 3265-3273.

29. Kent, J. L., \& Dowling, R. (2013). Puncturing automobility? Carsharing practices. J Transp Geogr, 32, 86-92.

30. Magoutas, M. et al., 2017. Deliverable 2.1 -state-of-the-art-report of the EU H2020-funded project MaaS4EU.

31. Kamargianni, M., Matyas, M., Li, W., Muscat, J., Yfantis, L., 2018. The MaaS dictionary. MaaSLab, Energy Institute, University College London. Available at: www.maaslab.org

32. Martin, E., Shaheen, S. A., \& Lidicker, J. (2010). Impact of Carsharing on household vehicle holdings: Results from north American shared-use vehicle survey. Transportation Research Record: Journal of Transportation Research Board, 2143, 150-158.

33. Matyas, M., and Kamargianni, M. (2017b) 'A holistic overview of the mobility as a service ecosystem' presented at the transportation research conference, Hungary, march 30-31.

34. Matyas, M., \& Kamargianni, M. (2018a). The potential of mobility as a service bundles as a mobility management tool. Open Access: Transportation.

35. Matyas, M., \& Kamargianni, M. (2018b). Survey Design for Exploring Demand for mobility as a service plans. Open Access: Transportation.

36. Monsere, C. M., McNeil, N., \& Dill, J. (2012). Multiuser perspectives on separated, on-street bicycle infrastructure. Transp Res Rec, 2314(1), 22-30.

37. Nawangpalupi, C., \& Demirbilek, O. (2008). Investigation of the drivers and the barriers for travel behaviour changes and analysis of the impact: A case study of car sharing in Australia. The International Journal of Environmental, Cultural, Economic \& Social Sustainability, 4(4), 1-12.

38. Parkin, J., Wardman, M., \& Page, M. (2007). Models of perceived cycling risk and route acceptability. Accid Anal Prev, 39(2), 364-371.

39. Polydoropoulou, A., Kamargianni, M. and Tsirimpa, A. (2013) 'Car use addiction vs. ecological consciousness: Which one prevails on mode choice behavior?' In book: Travel behaviour research (IATBR), editors: Roorda, M. and E. miller, pp. 128-139.

40. Schlich, R., \& Axhausen, K. W. (2004). Habitual travel behaviour: Evidence from a six-week travel diary. Transportation, 30(1), 13-36.

41. Shaheen, S. A., Cohen, A. P., \& Chung, M. (2009). North American Carsharing: 10-year retrospective. Transportation Research Record: Journal of Transportation Research Board, 2110, 35-44.

42. Smith, G., Sochor, J. \& Karlsson, I. M. (2017) Mobility as a service: Implications for future mainstream public transport. Presened at Thredbo15 international conference series on competition and ownership in land passenger transport, Stockholm, Sweden.

43. Smits, G., Sochor, J., \& Karlsson, M. A. (2017). Procuring mobility as a service: Exploring dialogues with potential bidders in West Sweden. Montreal: Presented at ITS World Congress.
44. Sochor, J., Karlsson, I. C. M., \& Strömberg, H. (2016). Trying out mobility as a service: Experiences from a field trial and implications for understanding demand. Transportation Research Record: Journal of the Transportation Research Board, 2542, 57-64.

45. Sochor, J., Strömberg, H., \& Karlsson, M. A. (2015). Implementing mobility as a service: Challenges in integrating user, commercial, and societal perspectives. Transportation Research Record: Journal of the Transportation Research Board, 2536, 1-9.

46. Steg, L. (2005)' Car use: lust and must. Instrumental, symbolic and affective motives for car use' Transportation Research Part A: Policy and Practice, 39(2-3), pp. 147-162.

47. Stevenson, M., Thompson, J., de Sá, T. H., Ewing, R., Mohan, D., McClure, R., Roberts, I., Tiwari, G., Giles-Corti, B., Sun, X., \& Wallace, M. (2016). Land use, transport, and population health: Estimating the health benefits of compact cities. Lancet, 388(10062), 2925-2935.

48. Gärling, T., \& Steg, L. (2007). Threats from Car traffic to the quality of urban life: Problems, causes, and solutions. Amsterdam: Elsevier.

49. Yau, A., \& Mahn, A. (2015). Sharing is dubious, it Won'T work! Exploring the barriers towards collaborative consumption of free floating Car. ACR North American Advances: Sharing.

50. Woodcock, J., Tainio, M., Cheshire, J., O'Brien, O., \& Goodman, A. (2014). Health effects of the London bicycle sharing system: Health impact Modelling study. Br Med J, 348, 425

51. Matyas, M. and Kamargianni, M. 2019. The Potential of Mobility as a Service Bundles as a Mobility Management Tool. Transportation. 46(5), pp. 1951-1968

\section{Publisher's Note}

Springer Nature remains neutral with regard to jurisdictional claims in published maps and institutional affiliations.

\section{Submit your manuscript to a SpringerOpen ${ }^{\circ}$ journal and benefit from:}

- Convenient online submission

- Rigorous peer review

- Open access: articles freely available online

High visibility within the field

- Retaining the copyright to your article

Submit your next manuscript at $\boldsymbol{\nabla}$ springeropen.com 